\title{
INL Laboratory Scale Atomizer
}

C. R. Clark

G. C. Knighton

R. S. Fielding

N. P. Hallinan

January 2010

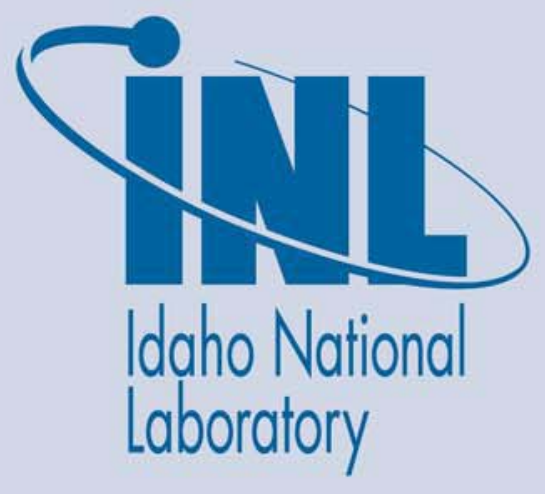

The INL is a U.S. Department of Energy National Laboratory operated by Battelle Energy Alliance 


\title{
INL Laboratory Scale Atomizer
}

\author{
C. R. Clark \\ G. C. Knighton \\ R. S. Fielding \\ N. P. Hallinan
}

January 2010

\section{Idaho National Laboratory Fuel Fabrication Development Idaho Falls, Idaho 83415}

http://www.inl.gov 


\section{DISCLAIMER}

This information was prepared as an account of work sponsored by an agency of the U.S. Government. Neither the U.S. Government nor any agency thereof, nor any of their employees, makes any warranty, expressed or implied, or assumes any legal liability or responsibility for the accuracy, completeness, or usefulness, of any information, apparatus, product, or process disclosed, or represents that its use would not infringe privately owned rights. References herein to any specific commercial product, process, or service by trade name, trade mark, manufacturer, or otherwise, does not necessarily constitute or imply its endorsement, recommendation, or favoring by the U.S. Government or any agency thereof. The views and opinions of authors expressed herein do not necessarily state or reflect those of the U.S. Government or any agency thereof. 


\section{CONTENTS}

ABSTRACT, SUMMARY, FOREWORD, AND ACKNOWLEDGEMENTSError! Bookmark not defined.

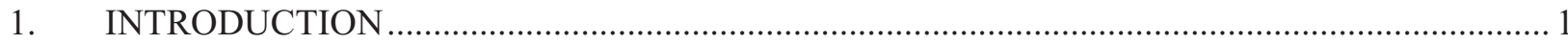

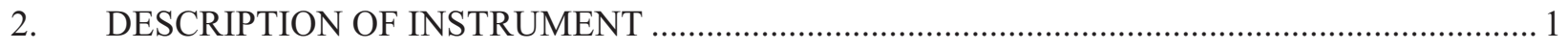

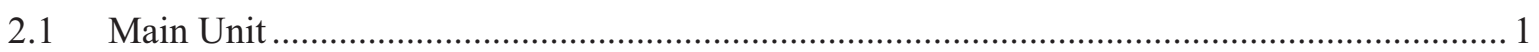

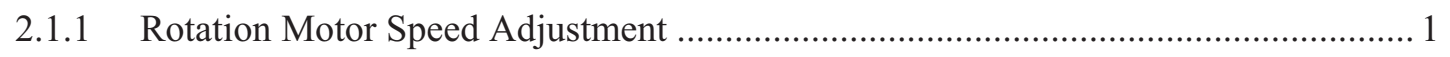

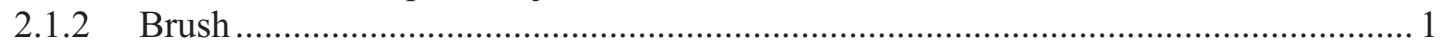

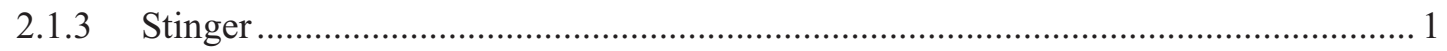

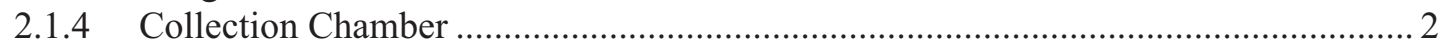

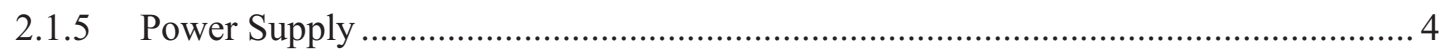

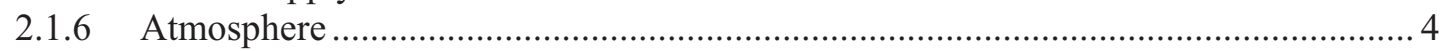

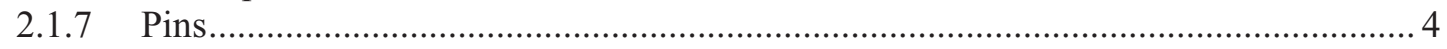

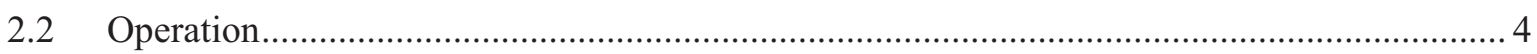

Appendix A-Information on Selected Off the Shelf Parts.................................................................... 5

\section{FIGURES}

Figure 1. (Left)Tool post grinder mounted vertically with collet attached. (Right) close-up of collet. Note the heavy base that the unit is mounted to. Note also the Lexan barrier that electrically isolates the bearing shaft from the motor.

Figure 2. (Left) close-up of variable transformer (also mounted to base). (Right) a Lexan shield placed around moving parts for safety during operation.

Figure 3 Collection Chamber. (Left) Top view-powder collects in this area. Center raised region is sized so as to cover only a minimal amount of the rotating pin while covering the collet. (Right) bottom view. The pipe is sized to fit over the top part of the bearing shaft.

Figure 4. (Left) Collection chamber lid and stinger. The lid is made of thin gauge Lexan and is sized to fit inside the chamber. The lid is held in place by a series of tabs around the perimeter. (Right) close-up of stinger position mount on lid. Note electrode holder (electrode not present) with set screw for holding tungsten in place. The stinger can be positioned at different heights or moved in an arc around the mounting point.

Figure 5. Bearing shaft and brush. (Left) a different view of the motor and shaft. Note the collar located below the collet to allow a good fit of the collection chamber. Note also the brush assembly (partially obscured) at the base of the bearing shaft. (Right) close-up of the brush assembly. A copper stub has been joined to the base of the bearing shaft (the stub turns with the shaft). A piece of copper is bent to hold a small block of graphite (the graphite is considered a consumable) and can be bent to adjust tension. The electrical lead is attached to the graphite by means of a welding lead. 


\section{INL Laboratory Scale Atomizer \\ 1. INTRODUCTION}

A laboratory scale atomizer has been built at the Idaho National Laboratory. This has proven useful for laboratory scale tests and has been used to fabricate fuel used in the Reduced Enrichment for Research and Test Reactors (RERTR) irradiation experiments. This instrument evolved over time with various improvements being made 'on the fly' in a trial and error process. It is capable of making $\sim 20 \mathrm{~g}$ of powder per run. This apparatus was designed built primarily by G. C. Knighton with input from N. P. Hallinan, B. A. Park, R. S. Fielding, M. D. Chapple and C. R. Clark.

\section{DESCRIPTION OF INSTRUMENT 2.1 Main Unit}

A tool post grinder ${ }^{a}$ has been modified to turn the alloy pin. The bearing shaft was electrically isolated from the base of the unit with a piece of Lexan. The grinding wheel was replaced with a $1 / 4$ inch collet. The tool post grinder is then mounted on a base so the axis of rotation is vertical. The base must be massive so the rotation of the motor will not shake the equipment out of alignment (we use a massive steel disk so we have some mobility but it would be more stable if it were bolted to the floor).

\subsubsection{Rotation Motor Speed Adjustment}

The rotational speed is adjusted with the use of a variable transformer. We have noticed a vibrational harmonic that forms from around 40,000 rpm. Since our optimal powder is formed at somewhere above this, we try to pass through this speed as quickly as possible.

\subsubsection{Brush}

To properly ground the alloy pin we transmit current through the bottom of the bearing shaft through a brush arrangement. We mounted a rounded copper stub on the bottom of the bearing shaft (it turns with the shaft). A small piece of graphite forms the transmitting media. The graphite will wear over time and is considered a consumable. A spring arrangement holds the graphite against the rotating copper shaft. The brush alignment is rather critical - too loose and the current will arc (although some sparks will always be generated) too tight and the motor will not turn freely. The tension needs to be adjusted from time to time. A grounding cable is attached to the secured end of the brush spring.

\subsubsection{Stinger}

The arc is generated through a standard tungsten-based welding electrode ( $\sim 3 / 16$ inch in diameter). The electrode is mounted with a set screw in a steel cylinder which is attached to a rack and pinion system that allows the operator to easily control the vertical travel during atomization. The rack and pinion system is attached to a mounting shaft with a set screw that allows the height to be set at the operator's convenience allowing an optimal stroke setting for any pin height. The electrical current is transmitted through a welding cable electrically connected to the electrode.

a. Equipment specifics for the bulk of the off-the-shelf item used to fabricate the atomizer are found in Appendix A. 


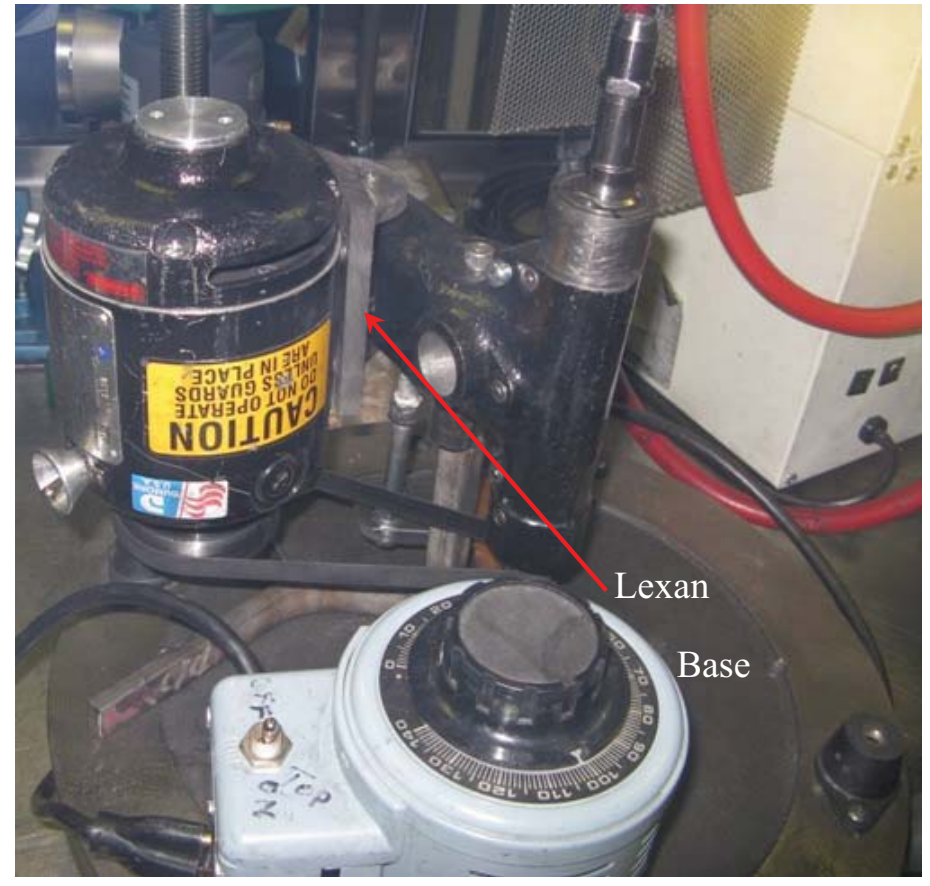

Figure 1. (Left)Tool post grinder mounted vertically with collet attached. (Right) close-up of collet. Note the heavy base that the unit is mounted to. Note also the Lexan barrier that electrically isolates the bearing shaft from the motor.

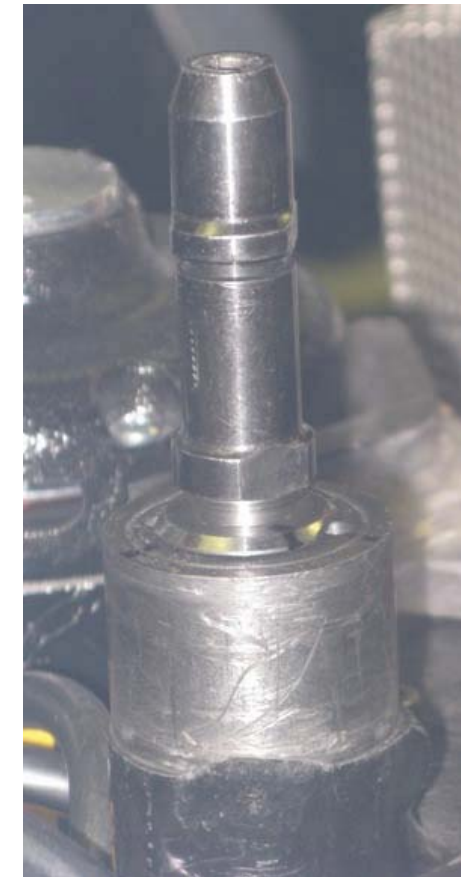

Figure 2. (Left) close-up of variable transformer (also mounted to base). (Right) a Lexan shield placed around moving parts for safety during operation.

\subsubsection{Collection Chamber}

The powder is collected in a stainless steel cylinder that is $\sim 14$ inches in diameter (a larger diameter would have been used but there were limitations in what could be transferred into the glovebox). The base of the unit is a pipe sized to fit over the collet system while allowing free rotation of the pin. A collar was placed on the bearing shaft, below the collet, to hold the chamber and the inside of the chamber has a hole size so as to be slightly larger than the diameter of the alloy pin. The height of the chamber is $\sim 4$ in-large enough to accommodate the entire length of the pin and allow the stinger plenty of travel. The chamber is constructed with stainless steel and care was taken to have smooth welds and corners to minimize powder holdup during operation. The lid of the chamber is made of Lexan which is lightweight, non conductive and allows the operator to see the process during operation. The lid is sized to fit inside the chamber and is held in place by a number of overlapping metal pieces mounted around the perimeter of the lid. There is a $\sim 2$ inch hole in the center of the lid which allows the stinger to reach the pin. The stinger is mounted on the lid so as to have an adequate range of movement - it can be pivoted to reach the pin with different setups. 


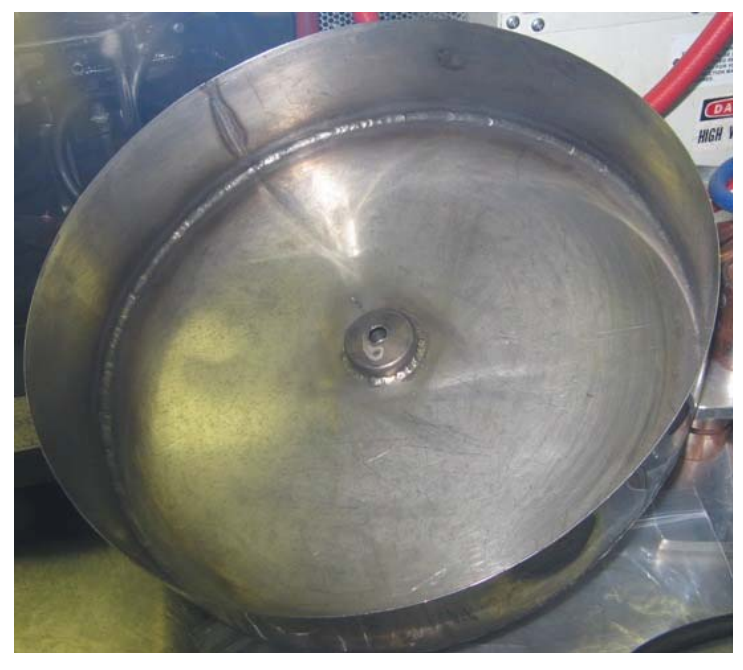

Figure 3 Collection Chamber. (Left) Top viewpowder collects in this area. Center raised region is sized so as to cover only a minimal amount of the rotating pin while covering the collet. (Right) bottom view. The pipe is sized to fit over the top part of the bearing shaft.

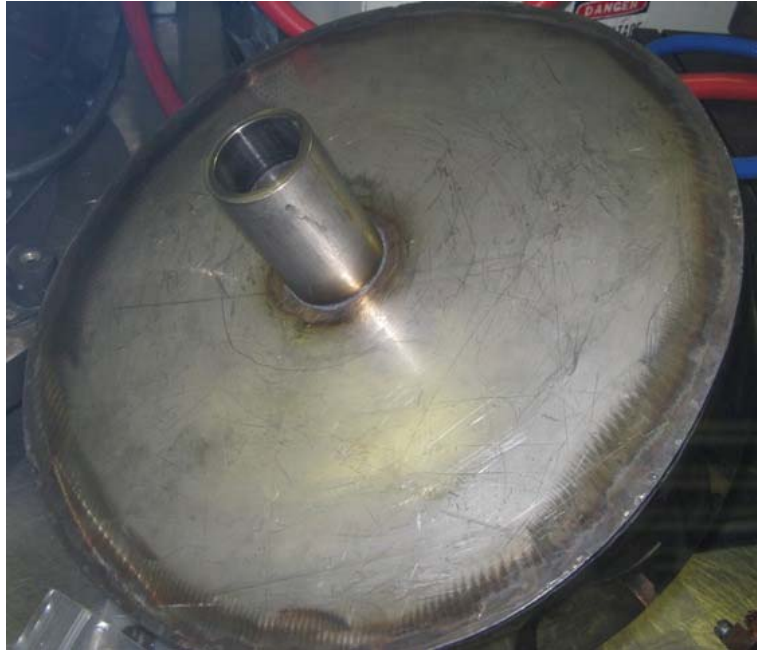

Figure 4. (Left) Collection chamber lid and stinger. The lid is made of thin gauge Lexan and is sized to fit inside the chamber. The lid is held in place by a series of tabs around the perimeter. (Right) closeup of stinger position mount on lid. Note electrode holder (electrode not present) with set screw for holding tungsten in place. The stinger can be positioned at different heights or moved in an arc around the mounting point.

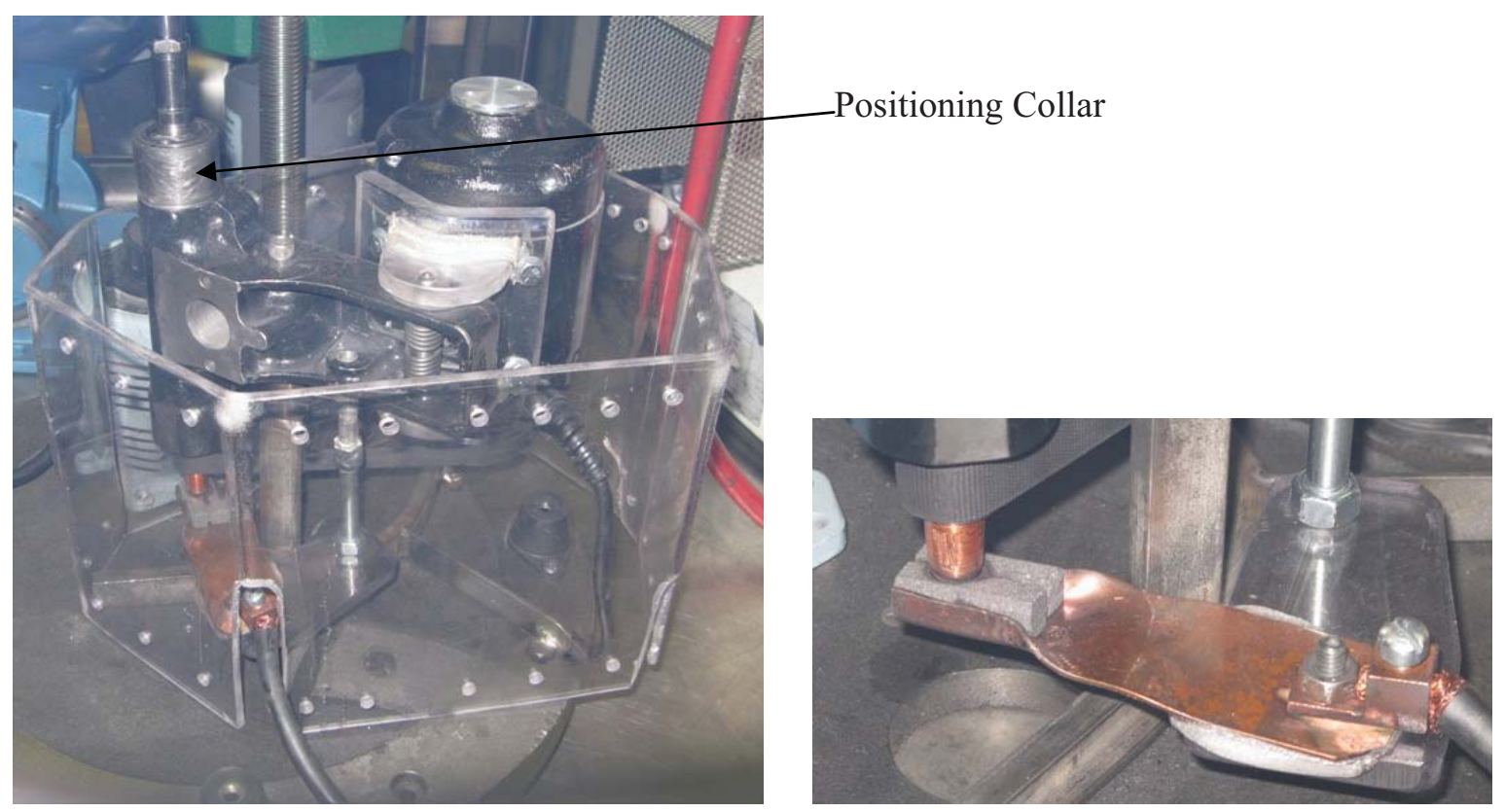

Figure 5. Bearing shaft and brush. (Left) a different view of the motor and shaft. Note the collar located below the collet to allow a good fit of the collection chamber. Note also the brush assembly (partially obscured) at the base of the bearing shaft. (Right) close-up of the brush assembly. A copper stub has been joined to the base of the bearing shaft (the stub turns with the shaft). A piece of copper is bent to hold a small block of graphite (the graphite is considered a consumable) and can be bent to adjust tension. The electrical lead is attached to the graphite by means of a welding lead. 


\subsubsection{Power Supply}

A DC power supply is used to generate the arc used to melt the rotating pin. Experience has shown that $\sim 75$ amps are needed for melting (the same power supply to make the pins (below) which uses 300 Amps). The operator uses a foot pedal to adjust the amperage. Some sort of starting aid is needed as scratch starting an arc is problematic. We use lift arc starting system as high frequency starting tends to adversely affect our glovebox systems.

\subsubsection{Atmosphere}

The atomizer is housed inside a purified inert (argon) atmosphere glovebox. While this limits space and makes handling much more difficult, it does allow atomization in a very good atmosphere (typically $<5 \mathrm{ppm} \mathrm{O}_{2}$ ). In the initial bench top studies (which used stainless steel as a melting surrogate) only very little work was done to inert the chamber atmosphere - it can be easily seen from pictures and designs described here that sealing the collection chamber atmosphere was not a high priority. With gaskets, tighter fits and a good flow of argon overpressure a suitable cover gas could be implemented.

\subsubsection{Pins}

The pins we have made for the atomization process are rather small: about 45 grams of uranium is the most our unit will handle. Experience with the use of larger pins has not worked as well with this design. Our pins are $3 / 8$ inch in diameter in the main part and have a $1 / 4$ inch diameter stub on the bottom to mount into the collet (this diameter was chosen because a larger lightweight collet could not be found and also to increase the fraction of the pin that was available to make powder). The pins are made by arcmelting. The alloy is made into a button on a standard copper hearth and after the necessary homogenization melts is melted into a copper mold hearth in the shape of the pin described above. A removable plug sits at the bottom allowing the cast pin to be easily removed.

\subsection{Operation}

The chamber is removed from the base unit and the pin is loaded into the collet. At this time the rotation is turned on to check the balance of the pin and how well the brush fits against the copper stubadjustments are made as needed. The chamber and lid are then placed on to the base unit and the stinger is adjusted to give the operator the desired range of movement. Prior to striking the arc a final rotational test is conducted.

The arc is established on the pin while is stationary and the operator must keep the power very low to avoid prematurely melting the pin. With the arc established the rotational motor is turned on and the pin is allowed to come up to full speed. Once the full rotational speed is established, the power is increased until the operator sees the pin starting to melt. The operator must carefully adjust the current and the distance the tip of the stinger is from the end of the pin. As the pin is consumed the stinger is brought down to maintain this distance. As the pin is melted near the collet the operator shuts off the current then turns off the rotational motor. 
Appendix A

\section{Information on Selected Off the Shelf Parts}




\section{Appendix A Information on Selected Off the Shelf Parts}

Note that the items listed may not be exactly what was used (in many cases a more recent model is now being manufactured) - they are provided only to give a general idea.

- Tool Post Grinder:

- Dumore Corporation

- $\quad$ Series 44 Tool post Grinder Model 8473

- Rack and Pinion Set

- Dremel Company

- Work Station Model 220

- Variable Transformer

- Instrument Service Equipment Inc.

- Variac Model 3PN1010B

- Power Supply

- Miller Electric Manufacturing Company

- Maxstar 350 welding power supply 